\title{
Cocaine and Amphetamine Interact at 5-HT Synapses through Distinct Mechanisms in Guinea-pig Prepositus Hypoglossi
}

\author{
Daniel H. Bobker and John T. Williams \\ Vollum Institute, Oregon Health Sciences University, Portland, Oregon 97201
}

Intracellular recordings were made from guinea-pig prepositus hypoglossi (PH) neurons in vitro. Neurons within this nucleus are innervated by terminals that release 5-HT (serotonin) to mediate an IPSP. Cocaine caused a concentration-dependent prolongation of that IPSP, while having no effect on either membrane potential or firing rate. Cocaine also caused an increase in the IPSP amplitude at lower concentrations $(\leq 1 \mu \mathrm{M})$ and a decrease at higher concentrations. The selective 5-HT uptake inhibitor fluoxetine also prolonged the IPSP duration but depressed the amplitude at all concentrations tested. The effects of cocaine on IPSP duration can be completely accounted for by inhibition of 5-HT uptake. The depression of the IPSP is most likely due to a presynaptic effect, because cocaine augmented the response to applied $5 \cdot \mathrm{HT}$.

Amphetamine (3-300 $\mu \mathrm{M})$, unlike cocaine, changed the membrane potential. At lower concentrations, it caused a ketanserin-sensitive depolarization, while higher concentrations resulted in a spiperone-sensitive hyperpolarization. The hyperpolarization was most likely caused by the evoked release of 5-HT, while the depolarization may have been due to a direct effect of amphetamine on $5-\mathrm{HT}_{2}$ receptors. Amphetamine also acted as a weak uptake inhibitor. The effects of cocaine, but not those of amphetamine, were observed at concentrations that are attained during self-administration.

Neurons of the prepositus hypoglossi $(\mathrm{PH})$ are located adjacent to the fourth ventricle and function as part of the extraocular motor system (Cheron and Godaux, 1987). We have recently described a 5-HT-mediated IPSP in this nucleus, as well as autoinhibition via a 5-HT,-subtype receptor (Bobker and Williams, 1990a). The PH contains few serotonergic neurons, but does receive a dense 5-HT innervation (Steinbusch, 1981; D. H. Bobker and J. T. Williams, unpublished observations). Therefore, the neurons in the nucleus $\mathrm{PH}$ and the 5-HT-mediated IPSP may be a good model for a 5-HT terminal field.

The goal of this investigation was to study the electrophysiological effects of cocaine and amphetamine in the PH. These

\footnotetext{
Received Dec. 6, 1990; revised Feb. 14, 1991; accepted Feb. 18, 1991.

We thank Drs. G. Harris, P. Osborne, and G. Postup Silinsky for comments on the manuscript. This work was supported by U.S. Department of Health and Human Services Grants DA 04523, MH 45003, and DA 00141 to J.T.W. and by NIH Grant HL 07596 to D.II.B.

Correspondence should be addressed to John T. Williams, Ph.D., Vollum Institute, mail code L474, 318 I Southwest Sam Jackson Park Road, Oregon Health Sciences University, Portland, OR 97201.

Copyright (C) 1991 Society for Neuroscience $0270-6474 / 91 / 112151-06 \$ 03.00 / 0$
}

two compounds have reinforcing properties in behavioral paradigms (Wise, 1984), and appear to act primarily through monoaminergic systems. Cocaine is a potent monoamine uptake inhibitor (Ross and Renyi, 1967, 1969), and its reinforcing properties correlate well with its affinity for the dopamine transporter (Ritz et al., 1987). Amphetamine is a relatively weaker uptake inhibitor, but it also has monoamine-releasing effects and direct agonist actions at some receptors (Homan and Ziance, 1981; Ritz and Kuhar, 1989). The sclf-administration of amphetamine and related analogs does not correlate with their affinity for the dopamine transporter, but may correlate negatively with the affinity for the 5-HT transporter (Ritz and Kuhar, 1989).

Recent studies have examined the electrophysiological actions of cocaine and amphetamine in a variety of brain regions. Cocaine inhibits monoaminergic neurons in the ventral tegmental area (Einhorn et al., 1988), substantia nigra (Lacey et al., 1990), dorsal raphe (Pitts and Marwah, 1986; Cunningham and Lakoski, 1988; Pan and Williams, 1989), and locus coeruleus (Pitts and Marwah, 1986; Surprenant and Williams, 1987). In the dopaminergic terminal field of the nucleus accumbens, however, cocaine had no effect by itself but enhanced the actions of applied dopamine and 5-HT (Uchimura and North, 1990). Amphetamine also has been shown to inhibit neurons of the substantia nigra (Mcrcuri ct al., 1989) and dorsal raphe (Pan and Williams, 1989) through evoked monoamine release. Here, we report the effects of cocaine and amphetamine in the 5-HT terminal field of the $\mathrm{PH}$.

Some of these results have appeared in preliminary form (Bobker and Williams, 1990b).

\section{Materials and Methods}

Intracellular recordings. The methods used were identical to those published previously (Bohker and Williams, 1990a). Male guinea pigs (200$350 \mathrm{gm}$ ) were anesthetized with halothane and killed. Slices of brainstem (thickness, $300 \mu \mathrm{m}$ ) containing the PH were cut in the horizontal plane in a vibratome, submerged in a tissue bath (vol, $0.5 \mathrm{ml}$ ), and superfused with physiological saline $(1.5 \mathrm{ml} / \mathrm{min})$ at $36^{\circ} \mathrm{C}$. The content of the superfusate was (in $\mathrm{mM}$ ) $\mathrm{NaCl}, 126 ; \mathrm{KCl}, 2.5 ; \mathrm{NaH}_{2} \mathrm{PO}_{4}, 1.2 ; \mathrm{MgCl}_{2}, 1.2$; $\mathrm{CaCl}_{2}, 2.4$; glucose, 11 ; and $\mathrm{NaHCO}_{3}, 24$; saturated with $95 \% \mathrm{O}_{2}, 5 \%$ $\mathrm{CO}_{2}$. The nucleus $\mathrm{PH}$ was located by its position adjacent to the fourth ventricle in the medulla. Microelectrodes were filled with $2 \mathrm{M} \mathrm{KCl}$ and were from 30 to $60 \mathrm{M} \Omega 2$ in resistance. Synaptic potentials were evoked using focal electrical stimulation (2-50 V, 0.01-0.3 msec; one stimulation per 30-60 sec) with bipolar tungsten electrodes placed in the slice approximately 500-1000 $\mu \mathrm{m}$ apart and within $300 \mu \mathrm{m}$ of the recording electrode. To study synaptic potentials, cells were held at a membrane potential from -55 to $-70 \mathrm{mV}$ by injecting hyperpolarizing current (10-150 pA).

Drug application. Drugs were applied in known concentrations by changing the perfusion solution to one that differed only in its content of drug. In some experiments, fast synaptic potentials were blocked 

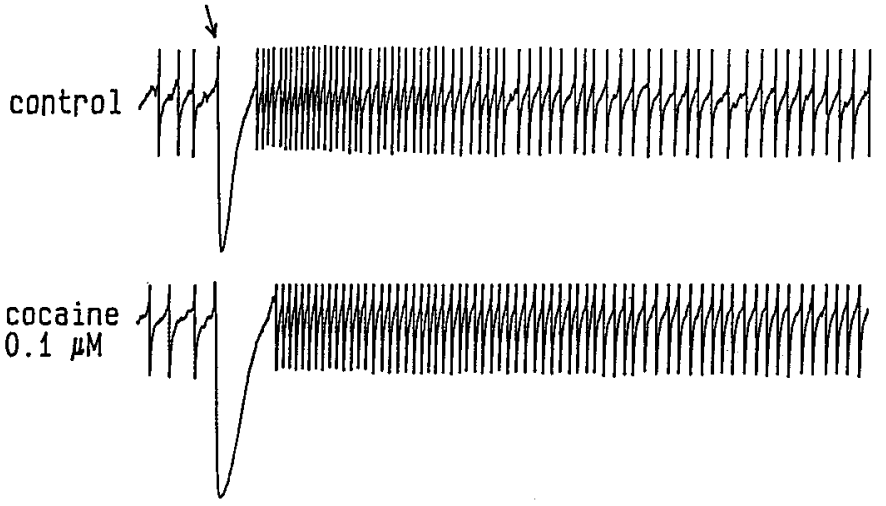

$1 \mu M$

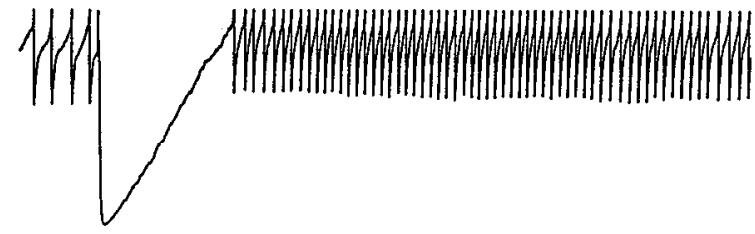

$10 \mu \mathrm{M}$

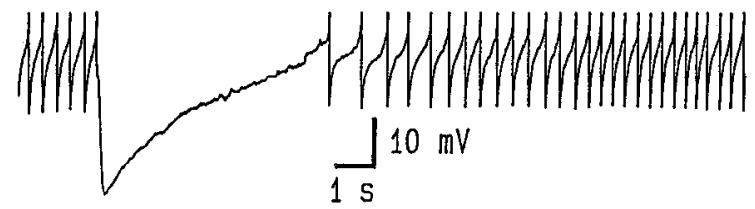

Figure 1. Cocaine prolonged the inhibition of firing caused by the IPSP. Top trace, Spontaneous activity is interrupted by an IPSP caused by electrical stimulation (at arrow; same for all four traces). Following the IPSP, firing rate was transiently increased by an s-EPSP. The amplitude of the action potentials has been truncated by the pen recorder. Lower three traces, Cocaine increased the duration of the IPSP and the resulting cessation of firing. Despite the reduced IPSP amplitude at 10 $\mu \mathrm{M}$, the net effect of cocaine was to prolong the interruption in firing rate. Note that cocaine also prolonged the effect of the s-EPSP.

using 5-cyano-7-nitroquinoxoline-2,3-dione (CNQX; $10 \mu \mathrm{M}$ ), kynurenate $(500 \mu \mathrm{M})$, strychnine $(500 \mathrm{nM})$, and picrotoxin $(100 \mu \mathrm{M})$. Drugs used were $5-\mathrm{HT}$, picrotoxin, kynurenate, $( \pm)$-cocaine $\mathrm{HCl}$, and $(+)$-amphetamine sulfate from Sigma Chemical Company; 8-hydroxydipropylaminotetraline $\mathrm{HBr}$ (8-OH-DPAT), spiperone, and ketanserin from Research Biochemicals Inc.; CNQX from Cambridge Research Biochemicals; and strychnine from Merck and Company.

Data analysis. Measurement of current and voltage were done with an Axoclamp-2A amplifier and recorded either directly onto a chart recorder or onto magnetic recording tape for later analysis. Measurements were made after three or four synaptic potentials were averaged. Calculation of half-duration was done by measuring the time from stimulation artifact to half-maximal amplitude during IPSP decay. Analysis of time constants for the IPSP was done using a least-squares regression program (pCLAMP, Axon Instruments, Inc.). The time course of the IPSP was modeled using the equation $V=A\left[e^{-t / \tau_{1}}-e^{-t / \tau}\right]$, where $V$ is membrane potential, $A$ is an arbitrary amplitude constant, $\tau_{1}$ is a time constant of activation, $\tau_{2}$ is the time constant of inactivation, and $t$ is time (see also Pan and Williams, 1989). The statistical significance of the difference between mean values of samples was determined using Student's $t$ test. All mean values are expressed as the standard error of the mean.

\section{Results}

These results are based on recordings made from 44 neurons. The properties of these cells have been reported previously (Bobker and Williams, 1990a; typc I cclls). Bricfly, guinca-pig PH neurons in the brain slice preparation are spontaneously active, with firing frequencies from 3 to $20 \mathrm{~Hz}\left(V_{\text {threshold }}=-50 \mathrm{mV}\right)$. Focal stimulation of the slice within $300 \mu \mathrm{m}$ of the recording electrode produced a sequence of synaptic potentials. A fast synaptic potential is followed by a slow IPSP and a slow EPSP (s-EPSP). The fast synaptic potential is mediated by the release of excitatory amino acids and GABA (Bobker and Williams, unpublished observations). The IPSP in this preparation has been described (Bobker and Williams, 1990a); it was caused by synaptically released $5-\mathrm{HT}$ acting upon $5-\mathrm{HT}_{1 \mathrm{~A}}$ receptors and had an amplitude of from 5 to $35 \mathrm{mV}$ and a duration of about $1 \mathrm{sec}$.

The s-EPSP was observed in 20 of 27 cells where synaptic potentials were studied (mean amplitude, $2.3 \pm 0.3 \mathrm{mV}$; duration, 15-35 sec). In all cells in which it was observed, the s-F.PSP was selectively blocked by the $5-\mathrm{HT}_{2}$ antagonist ketanserin $(1 \mu \mathbf{M})$. This allowed for study of the IPSP in isolation.

\section{Actions of cocaine}

Effects on membrane potential. Cocaine $(0.1-30 \mu \mathrm{M})$ had no effect on the rate of spontaneous firing $(n=3)$. When neurons were hyperpolarized beyond threshold with injected current ( $V_{\text {membrane }}=-60$ to $-75 \mathrm{mV}$ ), cocaine had no effect on membrane potential $(n=15)$.

Effects on IPSP. Focal stimulation of spontaneously firing cells caused synaptic potentials that resulted in a brief cessation of firing $(0.5-1 \mathrm{sec})$, followed by a longer period of increased firing rate $(15-35 \mathrm{sec})$. This was due to the slow IPSP-EPSP sequence. Cocaine augmented both of these synaptic potentials at concentrations up to $1 \mu \mathrm{M}$ and depressed them at higher concentrations. At all concentrations, however, cocaine prolonged the duration of the IPSP and the resulting cessation in spontaneous firing (Fig. 1).

To permit a quantitative analysis of the effect of cocaine on the 5-HT-mediated IPSP, neurons were hyperpolarized beyond threshold with injected current ( $n=13)$. In addition, fast synaptic potentials were blocked with a combination of receptor antagonists (see Materials and Methods), and the s-EPSP was blocked with ketanserin $(n=13)$. At lower concentrations $(0.1-$ $1 \mu \mathrm{M}$ ), cocaine increased the maximal amplitude of the IPSP. The peak effect was about a $40 \%$ increase above control, observed at $0.3 \mu \mathrm{M}$. Concentrations greater than $1 \mu \mathrm{M}$ reduced the IPSP to less than that of control (Fig. 2). At $30 \mu \mathrm{M}$, the IPSP was nearly completely blocked. All effects of cocaine reached steady state within 5 min and reversed upon washout after 30 $\min$.

The IPSP duration was prolonged by cocaine. In 5 of the 13 cells, data were analyzed to determine the effect of cocaine on the time constants of activation $\left(\tau_{1}\right)$ and deactivation $\left(\tau_{2}\right)$, and time-to-peak amplitude (TTP) of the IPSP. Cocaine had no significant action on $\tau_{1}$, while $\tau_{2}$ and TTP were increased in a concentration-dependent manner. At $10 \mu \mathrm{M}$ cocaine, $\tau_{2}$ had increased to about $1150 \%$ of control (Table 1).

The effect of cocaine on the IPSP duration was also determined for all 13 cells using the half-duration time. These results were similar to those obtained using the time constant of decay. In control, the IPSP amplitude was $12.0 \pm 1.9 \mathrm{mV}$, and halfduration was $0.57 \pm 0.04 \mathrm{sec}(n=13)$. Cocaine $(10 \mu \mathrm{M})$ caused a $593 \pm 70 \%$ increase in half-duration, with an $\mathrm{EC}_{50}$ of $1.2 \mu \mathrm{M}$ (Fig. 2).

Effects on applied 5-HT. Cocaine augmented the hyperpolarizing cffect of applied 5-HT. As we have reported previously, cocaine $(10 \mu \mathrm{M})$ caused a 64 -fold left shift in the 5 -HT concentration-response curve and decreased the $\mathrm{EC}_{50}$ from $8.6 \mu \mathrm{M}$ to $135 \mathrm{~nm}$ (Bobker and Williams, 1990a). Cocaine had no signif- 
A

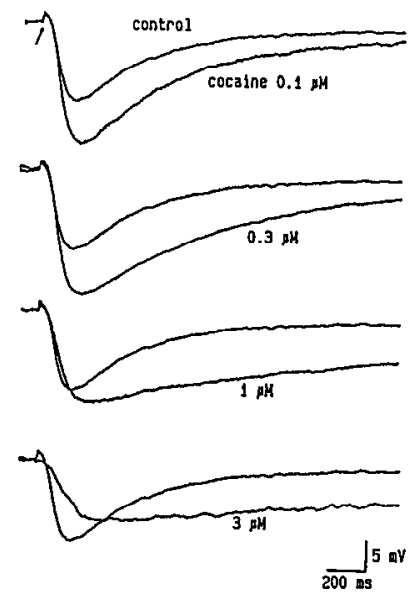

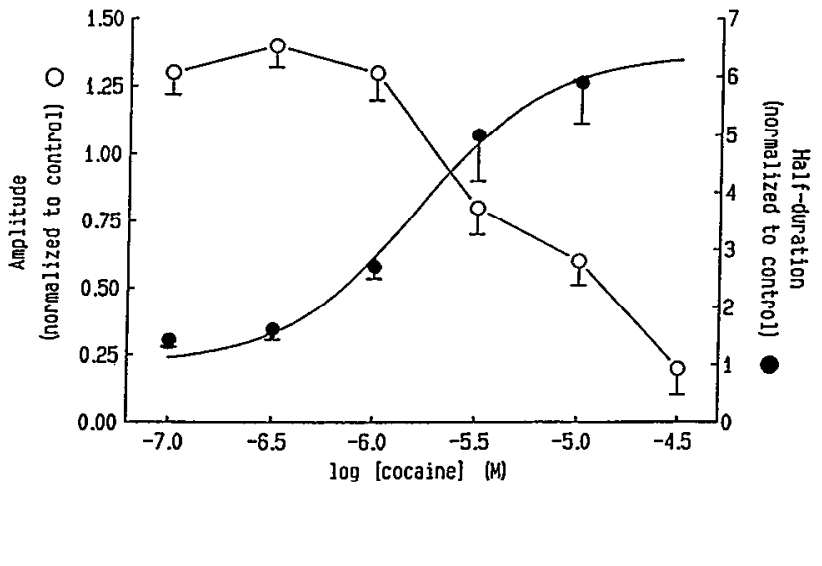

Figure 2. Cocaine effects on the IPSP. $A$, Overlapping traces of membrane potential show IPSP from control and from increasing concentrations of cocaine. Cocaine progressively prolonged the IPSP, while having a biphasic effect on amplitude. All data are from a single cell; membrane potential was $-70 \mathrm{mV}$. Antagonists of fast synaptic potentials were added to isolate the IPSP (see Materials and Methods). $B$, Plot of cocaine concentration versus normalized amplitude and half-duration. Data points represent 6-10 determinations. Error bars represent SEM. icant effect on the concentration-response curve of the 5-HT agonist 8-OH-DPAT (Fig. 3). The $\mathrm{EC}_{50}$ for 8-OH-DPAT was $16 \mathrm{nM}$ for control $(n=4)$ and $25 \mathrm{nM}$ for cocaine $(10 \mu \mathrm{M} ; n=$ 4).

\section{Actions of related compounds}

Cocaine is a nonselective monoamine uptake inhibitor and has local anesthetic actions. To delineate further the mechanism of the above actions, compounds with selective properties were studied. Fluoxetine $(0.3-10 \mu \mathrm{M})$, a selective 5-HT uptake inhibitor, caused a concentration-dependent prolongation of the IPSP half-duration and decrease in amplitude; at $10 \mu \mathrm{M}$, it increased the half-duration by $438 \pm 70 \%(n=4)$ and decreased the amplitude to $25 \pm 9 \%$ of control. However, unlike cocaine, no increase in IPSP amplitude was observed at the lower concentrations (Table 2$)$. The local anesthetic procaine $(10 \mu \mathrm{M})$ had no effect on the IPSP duration or amplitude $(n=3)$. Neither fluoxetine nor procaine had any effect on firing rate or membrane potential.

\section{Actions of amphetamine}

Effect on membrane potential. Amphetamine (3-300 $\mu \mathrm{M})$ had a biphasic effect on membrane potential. At 3 and $10 \mu \mathrm{M}$, amphetamine caused a small but reproducible depolarization of from 2 to $5 \mathrm{mV}$; concentrations greater than $10 \mu \mathrm{M}$ caused membrane hyperpolarization followed by a late depolarization (Fig. 4). The effects of the high concentrations of amphetamine mimicked the action of applied 5-HT (Bobker and Williams, 1990a, their Fig. 8B). Steady state was reached within $3 \mathrm{~min}$ of perfusion, and washout was complete within $10 \mathrm{~min}$.

The depolarizing action of amphetamine was completely blocked by prior application of ketanserin $(1 \mu \mathrm{M})$. Under these conditions, amphetamine only caused a hyperpolarization $(n=$ 3; Fig. 4B). The maximal hyperpolarization for amphetamine occurred at $300 \mu \mathrm{M}$ and was $17 \pm 3 \mathrm{mV}(n=6)$; this was usually $80-90 \%$ of the maximal response to 5-HT $(100 \mu \mathrm{M})$.

The hyperpolarizing action of amphetamine, like that of 5-HT, was completely blocked by spiperone (1 $\mu \mathrm{M} ; n=3)$. Noradrenaline $(10 \mu \mathrm{M})$, but not dopamine $(10 \mu \mathrm{M})$, also hyperpolarized these neurons. In idazoxan $(5 \mu \mathrm{M})$, noradrenaline had no effect on membrane potential. The hyperpolarization caused by amphetamine was not affected by idazoxan $(5 \mu \mathrm{M} ; n=2)$ or prazosin $(0.1 \mu \mathrm{M} ; n=3)$. In addition, neither the 5-HT-nor the amphetamine-induced hyperpolarization was significantly affected by pretreating the brain slice with reserpine $(n=3 ; 3 \mu \mathrm{M}$ for 2-4 hr). The cells studied from these slices did not have an IPSP despite typical hyperpolarizations to 5-HT. In a single experiment, a cell with a $15-\mathrm{mV}$ IPSP was perfused with reserpine $(10 \mu \mathrm{M})$, resulting in an $80 \%$ inhibition of the IPSP; the hyperpolarization to applied amphetamine, as well as to 5-HT, was unaflected by this treatment.

Effect on IPSP. Amphetamine inhibited the IPSP amplitude at all concentrations tested $(3-100 \mu \mathrm{M})$. In these experiments, the effect of amphetamine on membrane potential was negated by adjusting the injected current so as to maintain a constant potential. The concentration-response curve for this inhibitory effect was steep, with a small inhibition $(<5 \%)$ at $3 \mu \mathrm{M}$, and nearly complete block ( $>90 \%$ ) of the IPSP at $30 \mu \mathrm{M}$ (Table 2 ). Ketanserin did not change this effect of amphetamine.

Amphetamine also caused a weak prolongation of the IPSP, with $10 \mu \mathrm{M}$ increasing the half-duration to $121 \pm 6 \%$ of control. The effect on half-duration at higher concentrations could not be measured accurately due to the inhibition of the IPSP. These effects of amphetamine contrast with those of cocaine and fluoxetine, where uptake inhibition was more potent (Table 2).

\section{Effects on stimulus-response curves}

Experiments were performed to determine if the cocaine- and amphetamine-induced inhibition of the IPSP could be overcome by an increase in electrical stimulus strength. If the inhibition were fully surmountable, this could suggest that the mechanism was a presynaptic hyperpolarization. Control stim-

\section{Table 1. Effects of cocaine on the IPSP}

\begin{tabular}{lrllcc}
$\begin{array}{l}\text { Cocaine } \\
\text { concen- } \\
\begin{array}{l}\text { tration } \\
(\mu \mathrm{M})\end{array}\end{array}$ & $n$ & $\begin{array}{l}\text { Amplitude } \\
(\mathrm{mV})\end{array}$ & $\mathrm{TTP}(\mathrm{msec})$ & $\tau_{1}(\mathrm{msec})$ & \multicolumn{1}{c}{$\tau_{2}$ (msec) } \\
\hline 0 & 5 & $12.3 \pm 3.0$ & $187 \pm 3$ & $74 \pm 3$ & $446 \pm 45$ \\
0.1 & 4 & $18.0 \pm 5.7$ & $209 \pm 11$ & $81 \pm 5$ & $664 \pm 99$ \\
0.3 & 3 & $18.3 \pm 5.5$ & $242 \pm 21$ & $78 \pm 4$ & $950 \pm 86$ \\
1.0 & 5 & $15.2 \pm 3.1$ & $308 \pm 36$ & $86 \pm 11$ & $2310 \pm 219$ \\
3.0 & 5 & $10.8 \pm 2.7$ & $341 \pm 46$ & $91 \pm 9$ & $3870 \pm 1240$ \\
10.0 & 3 & $7.7 \pm 2.7$ & $451 \pm 109$ & $111 \pm 36$ & $5110 \pm 1530$
\end{tabular}




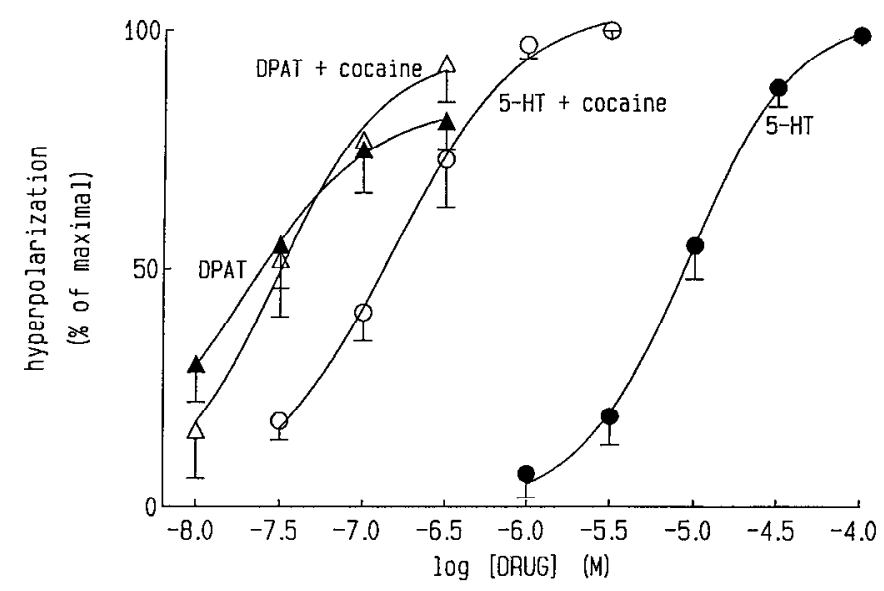

Figure 3. Cocaine augmented the effect of applied 5-HT. Cocaine (10 $\mu \mathrm{M}$; open circles) caused a 64-fold left shift of the 5-HT concentrationresponse curve (solid circles). 8-OH-DPAT (DPAT; solid triangles), which acts as a partial agonist in this preparation, was unaffected by cocaine (open triangles). All responses were normalized to the maximal response to 5 -HT $(100 \mu \mathrm{M} ; 18 \pm 3 \mathrm{mV} ; n=18)$. Data points represent from three to seven determinations for all curves, except 5-HT $(n=5-18)$. Error bars represent SEM. Some of these data have appeared previously (Bobker and Williams, 1990a). ulus-response curves were determined, followed by application of either cocaine or amphetamine $(10 \mu \mathrm{M})$. In all experiments except one, the maximal IPSP amplitude was reduced in an insurmountablc fashion. Cocainc causcd a $42 \pm 11 \%(n=6)$ decrease, while amphetamine caused a $53 \pm 15 \%(n=4)$ decrease in maximal amplitude (Fig. 5).

\section{Discussion}

This study describes the effects of cocaine and amphetamine on serotonergic transmission in the PH. Cocaine had no effect on membrane potential or spontaneous firing rate, while it enhanced the effects of both synaptically released and exogenously applied 5-HT. This is consistent with findings in other monoamine projection areas such as the hippocampus (Dunwiddie et al., 1988) and nucleus accumbens (Uchimura and North, 1990), but contrasts to the hyperpolarizing effect observed in dorsal raphe (Pitts and Marwah, 1986; Cunningham and Lakoski, 1988; Pan and Williams, 1989) and other monoaminergic nuclei (Surprenant and Williams, 1987; Williams and Lacey, 1989; Lacey et al., 1990). The postsynaptic 5-HT reccptor in both the PH and dorsal raphe is the $5-\mathrm{HT}_{\mathrm{IA}}$ subtype; therefore, it is not likely that the cocaine-induced hyperpolarization in dorsal raphe is
Figure 4. Amphetamine affected the membrane potential. $A$, In control, amphetamine caused a small depolarization at $10 \mu \mathrm{M}$ and a hyperpolarization followed by a late depolarization at higher concentrations. $B$, In ketanserin (1 $\mu \mathrm{M}$ ), amphetamine hyperpolarized $\mathrm{PH}$ cells at all concentrations, and there was no late depolarization. $C$, Concentration-response curves in control (open circles) and in the presence of ketanserin (solid circles). The maximal hyperpolarization was $17 \pm 3 \mathrm{mV}$. The ordinate is the amplitude of the hyperpolarization; negative values indicate a depolarization. Data points represent from two to six determinations. Error bars represent SEM. Broken lines in $A$, $B$, and $C$ indicate the control $\mathrm{mcm}-$ brane potential.
A control
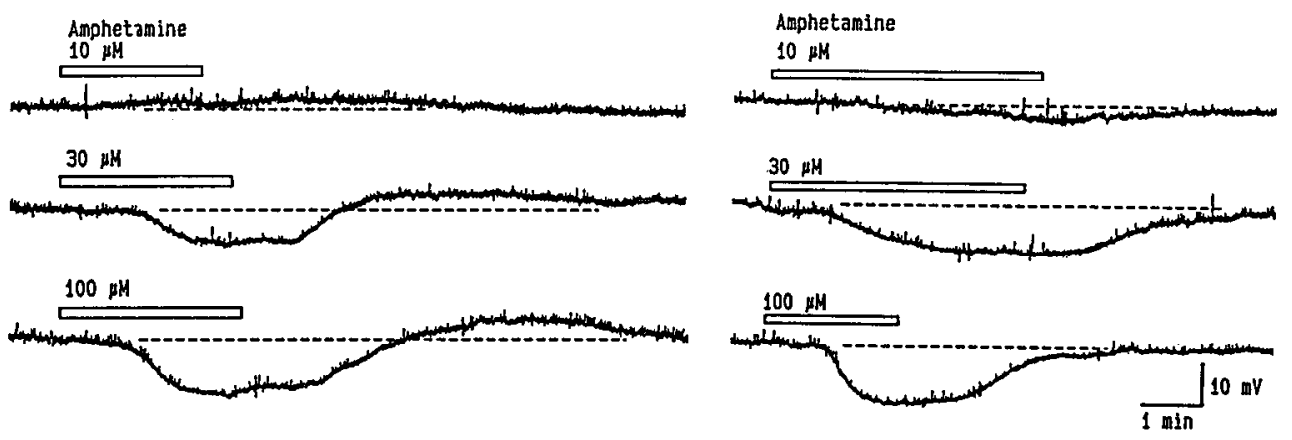

C

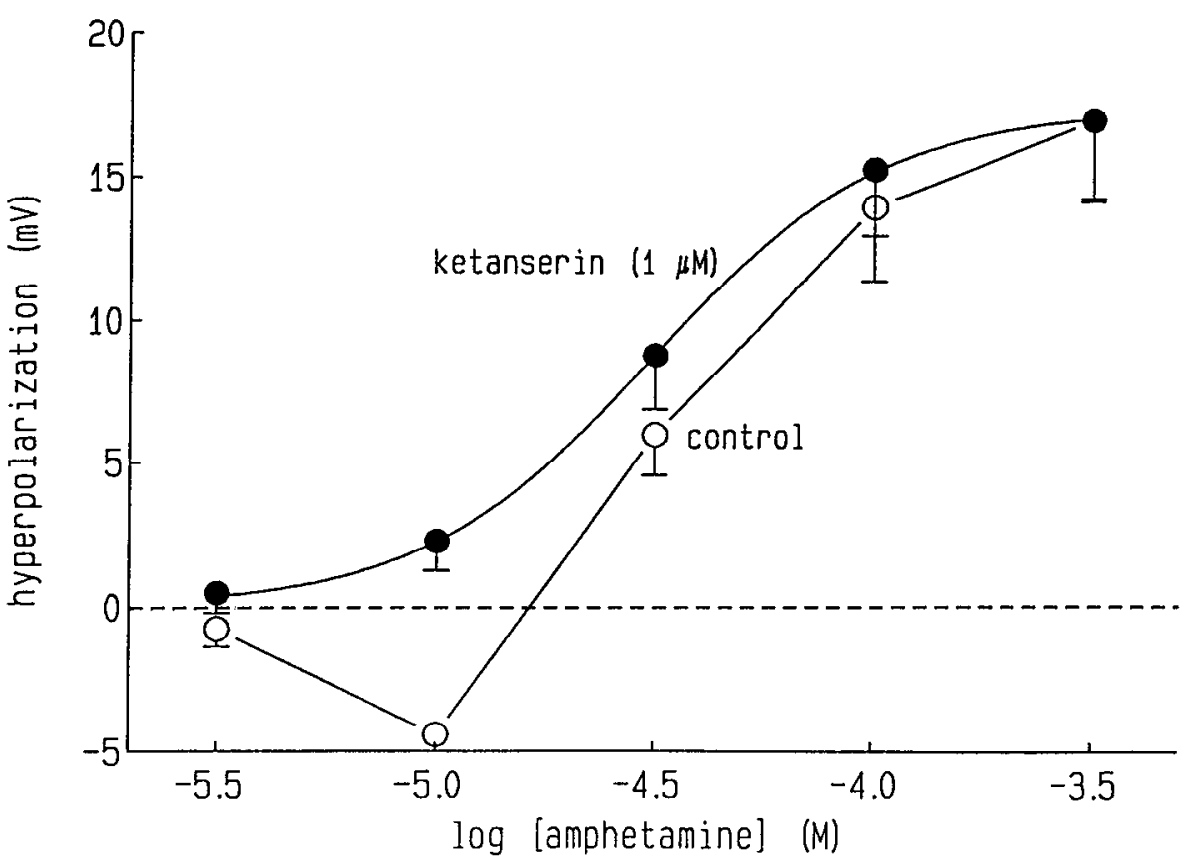


due to direct receptor stimulation, but more likely secondary to uptake inhibition with subsequent accumulation of 5-HT. The source of the 5-HT in the dorsal raphe was inferred to be a somatic and/or dendritic pool and could account for the lack of a cocaine-induced hyperpolarization in $\mathrm{PH}$.

The effect of cocaine on IPSP duration is fully accounted for by uptake blockade. The time constant for activation was unaffected, while that for inactivation was prolonged in a concentration-dependent manner. The effect of cocaine on IPSP amplitude is more difficult to account for. A simple model predicts that increasing the inactivation time should progressively increase the IPSP amplitude. This analysis works well for cocaine concentrations $\leq 1 \mu \mathrm{M}$ (see Pan and Williams, 1989; Materials and Methods). Above $1 \mu \mathrm{M}$, however, the IPSP amplitude was depressed. This effect could not be accounted for by receptor antagonism, because cocaine caused a marked left shift of the 5-HT concentration-response curve at concentrations that nearly completely blocked the IPSP. (The left shift resulted from uptake inhibition, because the concentration-response curve to 8-OH-DPAT was not affected by cocaine.) Another potential explanation for cocaine's inhibition of the IPSP would be an anesthetic action (Dunwiddie et al., 1988). This is not likely, however, because procaine $(10 \mu \mathrm{M})$ was without effect in this preparation, whereas a 3-10-fold lower concentration of cocaine reduced the amplitude of the IPSP. Furthermore, this action of cocaine is observed with other uptake inhibitors such as fluoxetine and may therefore be due to a secondary effect of 5-HT. Fluoxetine, unlike cocaine, did not augment the IPSP amplitude as low concentrations. Similar findings were made in the dorsal raphe (Pan and Williams, 1989). We have not found an adequate explanation for this difference between the two uptake inhibitors.

The depression of the IPSP amplitude caused by cocaine is likely the result of a presynaptic inhibition through one of two mechanisms. The first could be a hyperpolarization of the presynaptic 5-HT-releasing neuron (somatic hyperpolarization), some of which are contained in the slice preparation. The concentration range that inhibited the IPSP in PH is the same as that which hyperpolarized dorsal raphe cells (Pan and Williams, 1989). However, the insurmountability of inhibition by cocaine with increascd stimulus intensity may suggest an additional mechanism, because presynaptic hyperpolarization alone would be expected to be fully surmountable by increased stimulation. A second mechanism would be the activation of presynaptic autoreceptors on nerve terminals. We have previously demonstrated the existence of these autoreceptors in both PH (Bobker and Williams, 1990a) and dorsal raphe (T. J. Grudt and J.

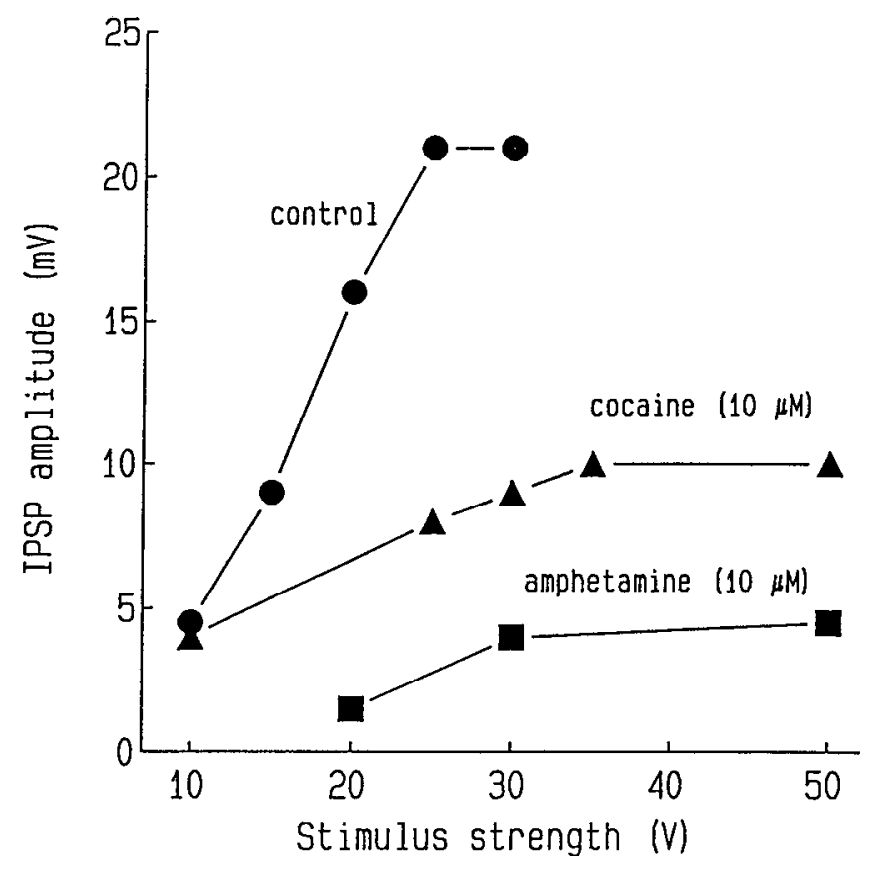

Figure 5. Plot of the stimulus-response curve for the IPSP. Cocaine $(10 \mu \mathrm{M}$; triangles) and amphetamine $(10 \mu \mathrm{M}$; squares) depressed the amplitude of the IPSP at all stimulus intensities, resulting in a reduced maximal amplitude. All data are from a single cell.

T. Williams, unpublished observations) and identified them as likely to be of the 5-HT $1 \mathrm{D}$ subtype (5-HT ${ }_{1 \mathrm{~B}}$ in rat dorsal raphe). Unfortunately, a selective antagonist has not been identified that would allow us to dissect out the role of the autoreceptor in the actions of cocaine.

The actions of amphetamine in $\mathrm{PH}$ were similar to those observed in dorsal raphe. Amphetamine had two separable effects on membrane potential: a depolarization at lower concentrations, and a hyperpolarization at higher concentrations. The depolarization was blocked by the $5-\mathrm{HT}_{2}$ antagonist ketanserin. This may have resulted from a direct agonist effect of amphetamine on $5-\mathrm{HT}_{2}$ receptors, rather than through the release of 5-HT, because applied 5-HT never resulted in a pure depolarization in these cells (i.e., a depolarization following the hyperpolarization was often seen with applied 5-HT). With ketanserin present, amphetamine caused only a hyperpolarization. While both 5-HT and noradrenaline hyperpolarized these neurons, only the 5-HT antagonist spiperone (and not the $\alpha$-adrenoceptor antagonists idazoxan or prazosin) blocked the amphetamine-

Table 2. Effect of uptake inhibitors on the IPSP amplitude and half-duration

\begin{tabular}{|c|c|c|c|c|c|c|}
\hline \multirow{2}{*}{$\begin{array}{l}\text { Concen- } \\
\text { tration } \\
(\mu \mathrm{M}) \\
\end{array}$} & \multicolumn{2}{|l|}{$\begin{array}{l}\text { Cocaine } \\
(\% \text { control })\end{array}$} & \multicolumn{2}{|l|}{$\begin{array}{l}\text { Fluoxetine } \\
\text { (\% control) }\end{array}$} & \multicolumn{2}{|c|}{$\begin{array}{l}\text { Amphetamine } \\
\text { (\% control) }\end{array}$} \\
\hline & Amplitude & Half-duration & Amplitude & duration & Amplitude & Half-duration \\
\hline $\begin{array}{r}0.3 \\
1.0 \\
3.0 \\
10.0 \\
30.0\end{array}$ & $\begin{aligned} 137 & \pm 8 \\
127 & \pm 10 \\
83 & +10 \\
56 & \pm 9 \\
16 & \pm 10\end{aligned}$ & $\begin{array}{l}162 \pm 19 \\
267 \pm 20 \\
500+80 \\
593 \pm 70 \\
N D\end{array}$ & $\begin{array}{l}97 \pm 12 \\
69 \pm 15 \\
52+12 \\
25 \pm 9 \\
N D\end{array}$ & $\begin{array}{l}115 \pm 8 \\
173 \pm 15 \\
330+60 \\
438 \pm 70 \\
N D\end{array}$ & $\begin{array}{l}\text { ND } \\
\text { ND } \\
97 \pm 11 \\
39 \pm 7 \\
6 \pm 2\end{array}$ & $\begin{array}{l}\text { ND } \\
\text { ND } \\
102 \pm 8 \\
121 \pm 6 \\
\text { ND }\end{array}$ \\
\hline
\end{tabular}

ND, not determined. For cocaine, $n=13$; for fluoxetine and amphetamine, $n=4-6$. 
induced hyperpolarization. These results, and amphetamine's low affinity for 5-H'T 1 receptors (Ritz and Kuhar, 1989), suggest that the amphetamine hyperpolarization is secondary to the release of endogenous 5-HT. The reserpine insensitivity of amphetamine implies release from a nonvesicular pool of 5-HT.

Amphetamine also had the properties of a weak 5-HT uptake inhibitor (see Table 2). This is consistent with its low affinity for the 5-HT transporter in radioligand-binding experiments (Ritz and Kuhar, 1989). Despite this, amphetamine also depressed the IPSP. This may have resulted from occlusion of the responsc, from presynaptic inhibition due to an amphetamineinduced hyperpolarization of raphe neurons, or from a direct inhibition of the mechanism of evoked transmitter release.

In conclusion, the psychostimulant drugs cocaine and amphetamine both affect 5-HT synaptic transmission in the $\mathrm{PH}$. The concentrations of cocaine used in this study were in the range of the plasma concentrations attained during self-administration (0.1-3 $\mu \mathrm{M}$; Javaid et al., 1978), while for amphetamine they were higher than seen with self-administration (low $\mu \mathrm{M}$; Ritz and Kuhar, 1989). The predominant action of cocaine resulted from uptake inhibition and was to prolong the effects of synaptically released 5-HT. This is distinct from its effects in monoaminergic nuclei, where cocaine also inhibits cell firing. Thus, the effects of cocaine in $\mathrm{PH}$ are dependent on the activity of serotonergic neurons. At lower concentrations, where there is little effect on neuronal excitability in raphe nuclei, cocaine enhances 5-HT synaptic transmission. At higher concentrations, 5-HT transmission might be depressed as raphe neurons are hyperpolarized away from threshold (Pan and Williams, 1989). Conversely, amphetamine had relatively weak effects on 5-HT synaptic potentials, caused the release of 5-HT at high concentrations and may be a direct $5-\mathrm{HT}_{2}$ agonist. Therefore, the effects of amphetamine on $\mathrm{PH}$ neurons were relatively independent of raphe neuronal activity.

\section{References}

Bobker DH, Williams JT (1990a) Serotonin-mediated inhibitory synaptic potential in guinea-pig prepositus hypoglossi and feedback inhibition by serotonin. J Physiol (Lond) 422:447-462.

Bobker DH, Williams JT (1990b) Actions of cocaine and amphetamine in nucleus prepositus hypoglossi. Soc Neurosci Abstr 16:72.

Cheron G, Godaux E (1987) Disabling of the occulomotor neural integrator by kainic acid injections in the prepositus-vestibular complex of the cat. J Physiol (Lond) 394:267-290.

Cunningham KA, Lakoski JM (1988) Electrophysiological effects of cocaine and procaine on dorsal raphe serotonin neurons. Eur J Pharmacol 148:457-462.

Dunwiddie TV, Proctor WR, Tyma J (1988) Local anaesthetic actions of cocaine: effects on excitatory and inhibitory synaptic responses in the hippocampus in vitro. $\mathrm{Br} \mathrm{J}$ Pharmacol 95:1117-1124.

Einhorn LC, Johansen PA, White FJ (1988) Electrophysiological effects of cocaine in the mesoaccumbens dopamine system: studies in the ventral tegmental area. J Neurosci 8:100-112.

Homan HD, Ziance RJ (1981) The effects of $d$-amphetamine and potassium on serotonin release and metabolism in rat cerebral cortex tissue. Res Commun Chem Pathol Pharmacol 31:223-240.

Javaid JI, Fischman MW, Schuster CR, Dekirmenjian H, Davis JM (1978) Cocaine plasma concentration: relation to physiological and subjective effects in humans. Science 202:227-228.

Lacey MG, Mercuri NB, North RA (1990) Actions of cocaine on rat dopaminergic neurones in vitro. Br J Pharmacol 99:731-735.

Mercuri NB, Calabresi P, Bernardi G (1989) The mechanism of amphetamine-induced inhibition of rat substantia nigra compacta neurones investigated with intracellular recording in vitro. $\mathrm{Br} \mathrm{J}$ Pharmacol 98:127-134.

Pan ZZ, Williams JT (1989) Differential actions of cocaine and amphetamine on dorsal raphe nuerons in vitro. J Pharmacol Exp Ther 251:56-62.

Pitts DK, Marwah J (1986) Electrophysiological effects of cocaine on central monoaminergic neurons. Eur J Pharmacol 131:95-98.

Ritz MC, Kuhar MJ (1989) Relationship between self-administration of amphetamine and monoamine receptors in brain: comparison with cocaine. J Pharmacol Exp Ther 248:1010-1017.

Ritz MC, Lamb RJ, Goldberg SR, Kuhar MJ (1987) Cocaine receptors on dopamine transporters are related to self administration. Science 23:1219-1223.

Ross SB, Renyi AL (1967) Inhibition of the uptake of tritiated catecholamines by antidepressant and related agents. Eur J Pharmacol 2: 181-186.

Ross SB, Renyi AL (1969) Inhibition of the uptake of tritiated 5-hydroxytryptamine in brain tissue. Eur J Pharmacol 7:270-277.

Steinbusch HWM (1981) Distribution of serotonin-immunoreactivity in the central nervous system of the rat-cell bodies and terminals. Neuroscience 6:557-618.

Surprenant A, Williams JT (1987) Inhibitory synaptic potentials recorded from mammalian ncuroncs prolonged by blockade of noradrenaline uptake. J Physiol (Lond) 382:87-103.

Uchimura N, North RA (1990) Actions of cocaine on rat nucleus accumbens neurones in vitro. Br J Pharmacol 99:736-740.

Williams JT, Lacey MG (1989) Actions of cocaine on central monoamine neurons: intracellular recordings in vitro. Natl Inst Drug Abuse Res Monogr Ser 90:234-242.

Wise RA (1984) Neural mechanisms of the reinforcing action of cocaine. Natl Inst Drug Abuse Res Monogr Ser 50:15-33. 